\title{
Improving the effectiveness of explosives using a dispersed air gap
}

\author{
Ilyar Tukhtamov ${ }^{1, *}$, Nurken Beisebaev ${ }^{1}$, Bulat Bazhanov ${ }^{2}$, Asfandiyar Orynbay ${ }^{1}$, and Asel \\ Shampikova ${ }^{1}$ \\ ${ }^{1}$ Satpayev University, 050000, Almaty, Satpayev Str. 22a, Kazakhstan \\ ${ }^{2}$ Scientific-Production Enterprise "Interrin" LLP, 050044 Almaty, Karasai batyra Str. 146, Kazakhstan
}

\begin{abstract}
Various foreign companies produce a wide range of watercontaining explosive mixtures. Gelatinized suspension and water-gel mixtures are patronized in polyethylene packaging of different diameters, various energy additives are introduced, their density and volume concentration of energy are regulated over a wide range. Kazakhstan became one of the sovereign large mining countries of the world after gaining independence in 1991. The mining industry forms the basis of industry, the economy of the country as a whole. It achieved this situation through mining mainly by the open method (more than $70 \%)$.
\end{abstract}

\section{Introduction}

With the deepening of mining operations, the geological conditions of the developed deposits deteriorate, the content of the main useful components in the ore decreases, their mineralogical composition becomes more complicated, the proportion of hard-to-concentrate ores increases, etc. In addition, ore bodies of many deposits are represented in the form of veins, formations of variable thickness with a varying angle of incidence, heterogeneous inclusions of unequal volume and different geometric shapes with visually unobservable contacts between them.

According to the conditions of use, emulsion explosives (EE), also related to watercontaining ones, successfully compete with suspension and water-gel mixtures. Emulsion explosives have been used in Kazakhstan for about 10 years. They consist of a so-called emulsion matrix, usually mixed with Ammonium nitrate or an Ammonium nitrate with diesel fuel mixture. Since emulsions of various compositions have high densities of $1.3-1.5 \mathrm{~g} / \mathrm{cm}^{3}$, detonation decays in the simplest ammonium nitrate mixtures. They are initiated using powerful intermediate detonators and stabilized by introducing gas generating additives (GGA) or microspheres made of glass, polymer, perlite, the content of which in the emulsion explosives does not exceed $4 \%$.

The advantages of emulsion explosives include their low cost, water resistance and stability. Due to the lack of expensive and scarce thickeners and structure-forming agents, emulsion explosives are much cheaper than other types of water-containing mixtures. Water

*Corresponding author: Tuhtamov-91@inbox.ru 
resistance of emulsion explosives is higher than suspension and water-gel formulations due to the fact that each droplet of the oxidizer solution is covered with a thin film of liquid fuel that protects the oxidizer from direct contact with water in the well [1].

\section{Methods}

At production sites of Scientific-Production Enterprise (SPE) "Interrin" LLP, a technology for the use of emulsion explosives sensitized with expanded polystyrene was developed and introduced into production. The introduction of expanded polystyrene into the explosive composition made it possible to control the explosive characteristics of EE of the interit 20 and interit 40 types in a wide range, which significantly expand their scope and methods of maintaining explosive materials in mining enterprises. The effectiveness of the application is due to the controlled characteristics of the used Inters containing expanded polystyrene.

The choice of polystyrene foam as a sensitizing component was based on the following. When a sensitizer is introduced into the explosive composition, the explosive characteristics of the compositions must be regulated over a wide range. According to the results of laboratory studies, when the plastic microspheres of $\varnothing 50-200$ microns are introduced into the composition of the type of interits, the emulsion matrix decomposes 10 days after the introduction, which does not allow guaranteeing the quality of products for industrial use. The use of GGA as a result of laboratory studies revealed the inappropriateness of their use for explosive compositions with an emulsion matrix content of less than $60 \%$, that is, there is no need to use GGA for explosives of the interit 20 and interit 40 type, since the content of the emulsion matrix in the compositions does not exceed $40 \%$ [2].

\section{Results and discussion}

Polygon and laboratory studies showed the results presented in Table 1, which show that the detonation rate of the interit compositions varies over a wide range depending on the bulk density of explosives (Fig. 1)

Since at the production sites of SPE "Interrin" LLP there are more than 6 stationary manufacturing sites (SMS), respectively, each of them should be equipped with its own point of preparation of a sensitizing additive that meets the conditions and requirements for the manufacture of explosives for SMS. The cost of equipment and components (raw materials) from foreign manufacturers does not allow their effective use in the conditions of SMS in the production of explosives in the immediate vicinity of the places of consumption of explosives.

The use of expanded polystyrene in the composition of granular explosives has been known since 1970, an example is explosives of the type of Jespolites developed and used in Zhezkazgan mines. Expanded polystyrene could effectively be used only by those enterprises where the manufacture or preparation of explosives was carried out at SPI. At this time, there was no available technology for industrial foaming of polystyrene for its use as a part of Granular Explosive (GE); therefore, its density was at least $15 \mathrm{~kg} / \mathrm{m}^{3}$. The effectiveness of the application and the detonation parameters of explosive compositions containing polystyrene foam are substantiated by such scientists as Zharkenov M.I., Nifadiev V.I., Kalinina N.M. and others.

A significant drawback in the industrial use of expanded polystyrene was its delamination during transportation and loading of the finished Granular Explosive (GE), this is due to the density difference between the granules of Ammonium Nitrate or other granular explosive component $\left(\mathrm{p}=800-950 \mathrm{~kg} / \mathrm{m}^{3}\right)$ compared to the density of expanded polystyrene $\left(\mathrm{p}=20-10 \mathrm{~kg} / \mathrm{m}^{3}\right)$ and the absence of binders (diesel fuel and oil did not provide the required 
adhesion of heterogeneous granules due to the low content of $5-8 \%$ ) [3].

Table 1. The detonation rate of Interites containing polystyrene foam.

\begin{tabular}{|c|c|c|c|}
\hline $\begin{array}{c}\text { Name of } \\
\text { explosive }\end{array}$ & $\begin{array}{c}\text { The content of expanded } \\
\text { polystyrene, } \%\end{array}$ & $\begin{array}{c}\text { Density, } \\
\mathrm{kg} / \mathrm{m}^{3}\end{array}$ & $\begin{array}{c}\text { Open charge detonation speed, } \\
\text { diameter } 170 \mathrm{~mm}, \mathrm{~m} / \mathrm{s}\end{array}$ \\
\hline \multirow{4}{*}{ interit 40 } & 0 & 1400 & 3900 \\
\cline { 2 - 4 } & 18 & 1212 & 4200 \\
\cline { 2 - 4 } & 25 & 1152 & 2700 \\
\cline { 2 - 4 } & 30 & 1112 & 2400 \\
\cline { 2 - 4 } & 35 & 1076 & 3200 \\
\cline { 2 - 4 } & 40 & 1041 & 4300 \\
\hline \multirow{5}{*}{ interit 20 } & 45 & 1009 & 4400 \\
\cline { 2 - 4 } & 50 & 1200 & 4500 \\
\cline { 2 - 4 } & 0 & 11523 & 3500 \\
\cline { 2 - 4 } & 10 & 976 & 2200 \\
\cline { 2 - 4 } & 20 & 941 & 3200 \\
\cline { 2 - 4 } & 25 & 908 & 3200 \\
\cline { 2 - 4 } & 30 & 878 & 3800 \\
\cline { 2 - 4 } & 35 & 850 & 2500 \\
\cline { 2 - 4 } & 40 & 798 & 2900 \\
\hline & 45 & 775 & 2600 \\
\hline
\end{tabular}

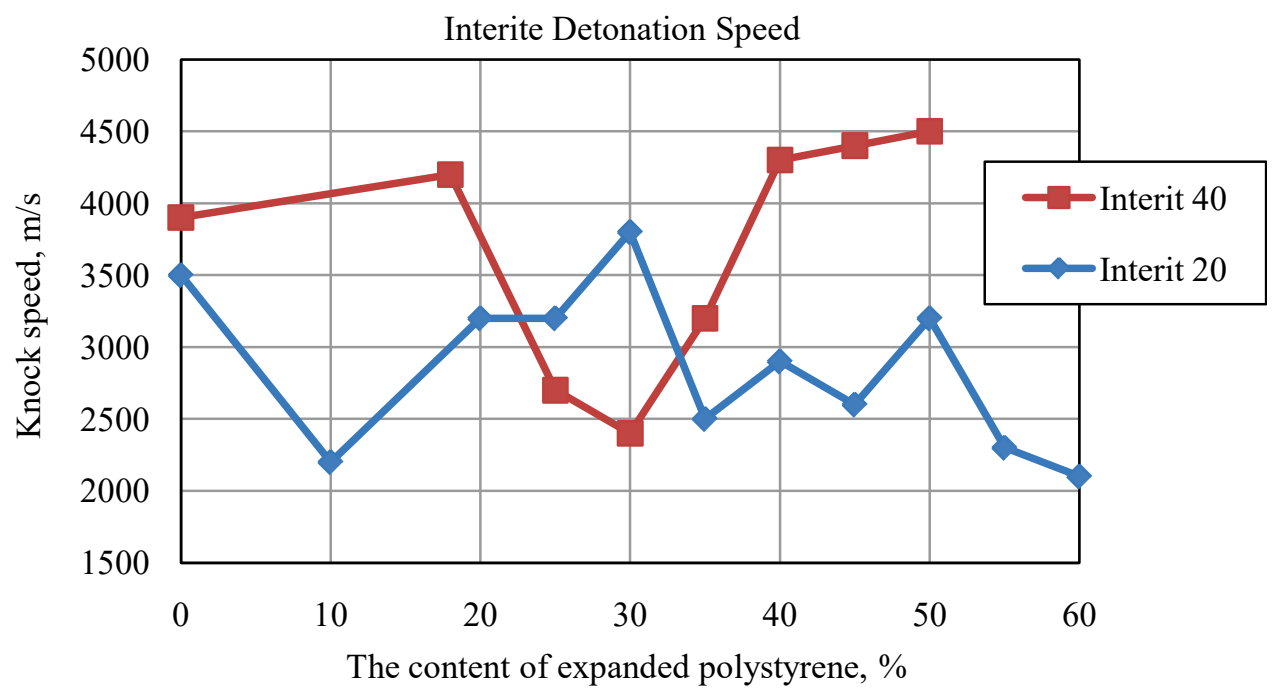

Fig. 1. The effect of polystyrene foam in the composition of interites on the detonation speed.

Today, modern technologies can significantly expand the field of application of effective methods for the production of explosive explosives and the manufacture of explosives with the required explosive indicators, to carry out effective use in production due to the refinement and improvement of manufacturing and use of explosives.

For the foaming of polystyrene, SPE "Interrin" LLP has developed and uses the UVP-02 installation at production sites. 
The technological process of the pre-foamer proceeds as follows. Raw materials (Polisterol sensitizing substance granules) are fed through the discharge valve of the hopper 3 to the screw feed 9. Using the screw feed, the raw materials enter the foaming tank 1 . The granules in the tank 1 are exposed to steam constantly coming from the steam generator 5.

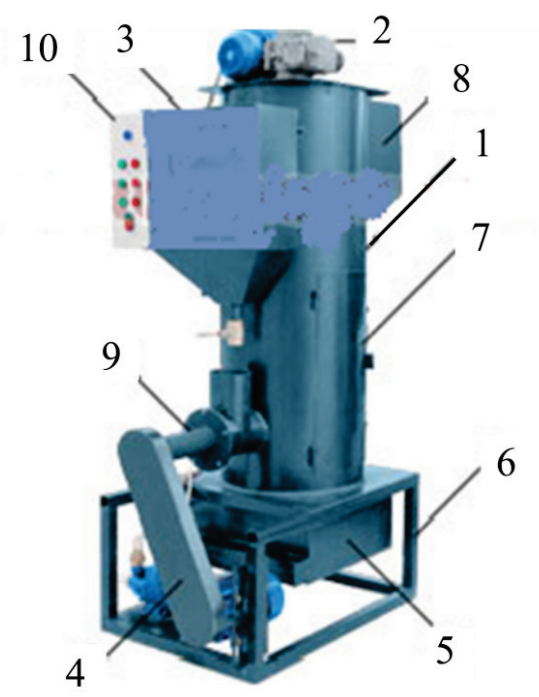

Fig. 2. The UVP-02 installation at production sites: 1- the foaming agent consists of a container for foaming polystyrene granules; 2- a drive for agitating granules; 3 - a hopper for raw materials (Polisterol sensitizing substance granules); 4- a drive for screw feed; 5 - of Polisterol sensitizing substance granules from a raw material hopper in a foaming tank, an integrated steam generator; 6- all of the above units are mounted on a single frame; 7- the foaming tank is equipped with an inspection hatch; 8- a discharge window; 9- screw conveyer; 10- control panel [4].

The steam generator 5 will replenish with water in automatic mode. When the water level in the steam generator reaches the lowest possible level, the water supply pump automatically turns on. Topping up water occurs until the upper permissible level is reached, after which the pump automatically switches off.

For steaming the entire mass of granules inside the tank 1 rotates the agitator blades of the granules. Due to this, steam acts on all granules, there are no stagnant zones. Under the pressure of expanding from the influence of the steam of the lower layers of the granules and newly fed under the pressure of the screw feed 9 of the raw material, the already foamed mass of the granules rises up the foaming tank and pours out through the discharge window 8 .

This equipment has an adjustable dosing of polystyrene into the foaming chamber and ejector transportation of polystyrene foam to the storage location and for the manufacture of explosives. Dosing of expanded polystyrene when mixed with explosives is performed using volumetric dispensers [5]. Storage and aging for the formation of stable granules is carried out in specialized tanks or bales with a volume of $1.5-2 \mathrm{~m}^{3}$.

The technology of mixing the components of explosives and expanded polystyrene corresponds to the general level of mechanization of the stationary manufacturing site.

Under various mining and technical conditions for the production of blasting, a comparative analysis for the main consumers of explosives worked out the composition of Interites at blasting by breed according to local conditions and presented in table 2 .

The share of the use of Intermit with expanded polystyrene at the production sites of SPE "Interrin" LLP is $90 \%$, or about 2 thousand tons per month.

The tests conducted suggest that the scope of interit containing $60-120 \%$ polystyrene foam, which are low-density, can significantly expand due to their use in contour blasting, 
blasting of coal and rocks with a strength of $f=3-7$ on a scale of prof. Protodyakonova M.M., development of dumps and tailings, shaking of heap leaching, with the aim of increasing the yield of minerals.

Table 2. The composition of Interites at blasting by breed according.

\begin{tabular}{|c|c|c|c|c|c|c|c|}
\hline $\begin{array}{l}\text { Name } \\
\text { of the field }\end{array}$ & 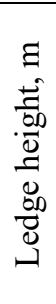 & 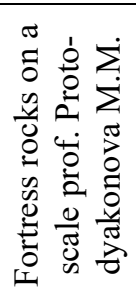 & $\begin{array}{c}\text { Name } \\
\text { of explosive }\end{array}$ & 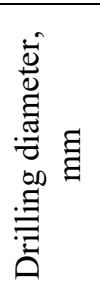 & 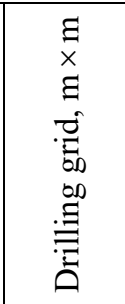 & 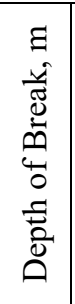 & 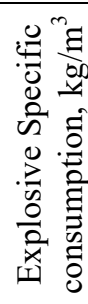 \\
\hline Atanzor Mine & 10 & $12-16$ & $\begin{array}{c}\text { interit } 40+40 \% \\
\text { expanded polystyrene - } \\
\text { lower part of the } \\
\text { charge. Interit } \\
20+30 \% \text { expanded } \\
\text { polystyrene upper part } \\
\text { of the charge }\end{array}$ & 156 & $5 \times 5$ & 1.5 & $\begin{array}{c}0.6- \\
0.7\end{array}$ \\
\hline Kentobe Mine & 10 & $18-20$ & $\begin{array}{c}\text { interit } 20+30 \% \\
\text { expanded polystyrene }\end{array}$ & 250 & $\begin{array}{l}6 \times 6 \\
6 \times 7 \\
\end{array}$ & 1 & $\begin{array}{l}0.8- \\
0.94\end{array}$ \\
\hline $\begin{array}{c}\text { Mine "Priorsky". } \\
\text { "50 years of } \\
\text { October" }\end{array}$ & 10 & $16-18$ & $\begin{array}{c}\text { interite } 40+18 \% \\
\text { expanded polystyrene }\end{array}$ & 170 & $4 \times 5$ & 1.5 & $\begin{array}{c}0.78- \\
0.91\end{array}$ \\
\hline $\begin{array}{l}\text { Building stone } \\
\text { quarry "Kapchagay- } \\
\text { skoye-2" }\end{array}$ & 10 & 14 & $\begin{array}{c}\text { interit } 20+40 \% \\
\text { expanded polystyrene }\end{array}$ & 110 & $4 \times 4$ & 0.5 & $\begin{array}{c}0.5- \\
0.6\end{array}$ \\
\hline $\begin{array}{l}\text { The quarries of the } \\
\text { North Zhezkazkaz- } \\
\text { gan Mine are Kip- } \\
\text { shakpai. Sredny- } \\
\text { Spassky and others. }\end{array}$ & 15 & $10-14$ & $\begin{array}{c}\text { interit } 20+30 \% \\
\text { expanded polystyrene }\end{array}$ & $\begin{array}{l}215- \\
250\end{array}$ & $\begin{array}{l}8 \times 8 \\
9 \times 9\end{array}$ & $\begin{array}{c}1.5- \\
2\end{array}$ & $\begin{array}{l}0.5- \\
0.65\end{array}$ \\
\hline Quarry Ayak-kojan & 10 & 14 & $\begin{array}{c}\text { interite } 40+18 \% \\
\text { expanded polystyrene }\end{array}$ & 1165 & $4 \times 4$ & 0.5 & $\begin{array}{c}0.8- \\
0.9\end{array}$ \\
\hline Druzhnoe Career & 12 & $12-16$ & $\begin{array}{c}\text { interit } 20+30 \% \\
\text { expanded polystyrene }\end{array}$ & 1130 & $3.5 \times 3.5$ & 0.5 & $\begin{array}{l}0.5- \\
0.65\end{array}$ \\
\hline
\end{tabular}

Among the directions for increasing the efficiency of drilling and blasting operations is the use of borehole charges with air gaps, which have become widespread as a result of large studies and industrial tests carried out by a group of scientific employees led by Academician N.V. Melnikova. The starting idea in the design of such charges is the redistribution of the energy of the explosion by reducing energy costs for plastic deformation and regrinding the medium near the charge, increasing the amount of energy that goes into destruction in a large volume. To date, many authors have published many works on the theory and practice of using charges of this design. As a result of these studies, the features of the destruction of the ledge in open cast mining, the methodology for determining the optimal charge parameters were identified, and it was also found that the factors determining the increase in the useful use of explosion energy in the charges of these structures include a decrease in the "pressure peak", an increase in the time of exposure to products detonation on the medium, the formation of a kind of hydrodynamic shutter from the oncoming products of detonation of the 
parts of the charge, the change in the distribution of pulses along the length of the well and the process of interaction of shock waves [6].

The increase in the duration of the explosion on the massif is one of the main directions in the intensification of crushing of rocks in quarries. Given this, we consider it possible to dwell on the relationship between the time of transfer of the energy of the explosion to the array and other quantities associated with the specific use of charges with air gaps in the quarries.

After the explosion of the charge under the influence of the pressure of the products of explosive decomposition in the array, the propagation of the intense field occurs, which causes deformation of the medium.

The magnitude of displacements (deformation) depends on the time of the explosion, therefore, the destruction and crushing of the rock mass. Therefore, it is necessary to choose such a duration of the explosion so that the deformation of the beaten rock is maximum [7].

As mentioned above, the degree of crushing of the rock will be better if the duration of the explosion in the medium is increased. An increase in the duration of an explosion can be accomplished in two ways: either by increasing the weight of the charge, or by dispersing the charge by air gaps [8]. Increasing the weight of the charge is irrational, since improving the overall effect of the explosion, the cost of work increases and a significant part of the energy is spent on unnecessarily overgrowing the rock mass near the well. However, to obtain a good effect, the charge can be taken less than the estimated weight with the help of the air gap.

Using air gaps, it is possible to increase the duration of the explosion without increasing the weight of the charge, thereby improving the fragmentation of the rock mass, since destructive deformations will occur in most of the massif.

To increase the duration of the explosion, you need to create an air gap of a certain length. The length of the air gap is determined by the formula:

$$
L=\frac{t_{3}}{\vartheta} \sqrt{\frac{2 \cdot p_{0}}{(n-1) \rho}} \cdot\left[1-\frac{v_{0}^{n-1}}{v_{1}}\right], \mathrm{m}
$$

where $p_{0}$ - the maximum pressure in the well equal to $10^{5} \mathrm{~kg} / \mathrm{cm}^{2} ; n$-adiabatic index $(n=1.05) ; \frac{v_{0}^{n-1}}{v_{1}}-$ the ratio of the charge volume to the volume of the charged part of the well, including the air gap; in all cases, this value is taken from $1 / 2$ to $1 / 3$, since it has a negligible effect on the final result of calculations; $\rho$ - explosive density, $\mathrm{kg} / \mathrm{cm}^{3} ; t_{3}-$ necessary increase time, sec; $\vartheta$ - coefficient taking into account the impact time $(3 \div 3.3)$.

Along with this, the complexity of using air gaps in borehole explosive charges is created, the main problem in the practice of blasting is the unreliability of the design of the air gap [9].

Having studied in detail the results obtained by a large group of scientists and practitioners, the staff of SPE "Interrin" LLP began their search and testing of methods and methods of charge dispersal.

The air gap device was created by a design consisting of a rod, a support and holding the upper charge of the cup. The air gap arrangement is shown in Figure 3.

The air gap device is made of plastic materials that meets the following requirements:

1. Safety in use.

2. Manufacturability, ie the relative simplicity of the design does not reduce the productivity of loading wells and does not increase labor costs.

3. Reliability of the design, which allows you to fix the top explosive charge and jamming.

4. Relatively low cost air gap device. 
5. The accuracy of the installation in the well in height to ensure a given charge design.

6. Possibility of use with all standard means of initiation.

7. Possibility of use in any mining conditions.

8. Low cost of the product, allowing cost-effective use of this method.

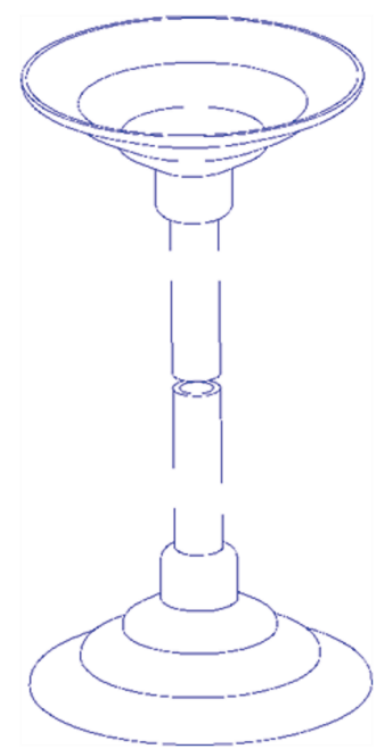

Fig. 3. Air gap device.

In order to determine the effectiveness of the use of designs of borehole charges with dispersed air gaps, we conducted pilot tests. The design of the borehole charge with an air gap is shown in Figure 4.

The effectiveness of such a charge design was tested in an opencast mining environment with rocks of various strengths at the Kentobe and Atansor iron ore quarries, 50 years of October copper deposit, Kotur-Bulak porphyry quarry, and Zlatapolsky crushed stone quarry and Ili.

The criterion for assessing the effectiveness of the borehole charge structures with air gaps were: a) the quality of the crushing of the rock mass, b) the development of the bottom of the ledge, c) the width and shape of the collapse, d) the specific consumption of explosives.

To obtain comparative results, wells with ordinary continuous core charges and charges with an air gap were located on one ledge on different sites in the same geological conditions and were included in one mass explosion.

During the test, part of the explosive charge in the wells was replaced by an air gap. The height of the charge column remained unchanged compared to the solid charge design. The charge was dispersed in the well in the following order: $65-75 \%$ of explosives were placed in the lower part of the well, then the air gap device was lowered, the rest of the charge and jamming were placed on top of it.

When using a solid charge design, the degree of use of the useful work of the explosion is very low. A continuous charge occupies $40-70 \%$ of the length of the well, and the rest of the well is filled with stemming, as a result of the destruction of the rock by an explosion occurs in the lower part of the ledge; in the upper part of the ledge, the rock is slightly destroyed, which sharply reduces the quality of crushing of the rock mass and leads to an increased yield of oversized material with a decrease in charge height. 


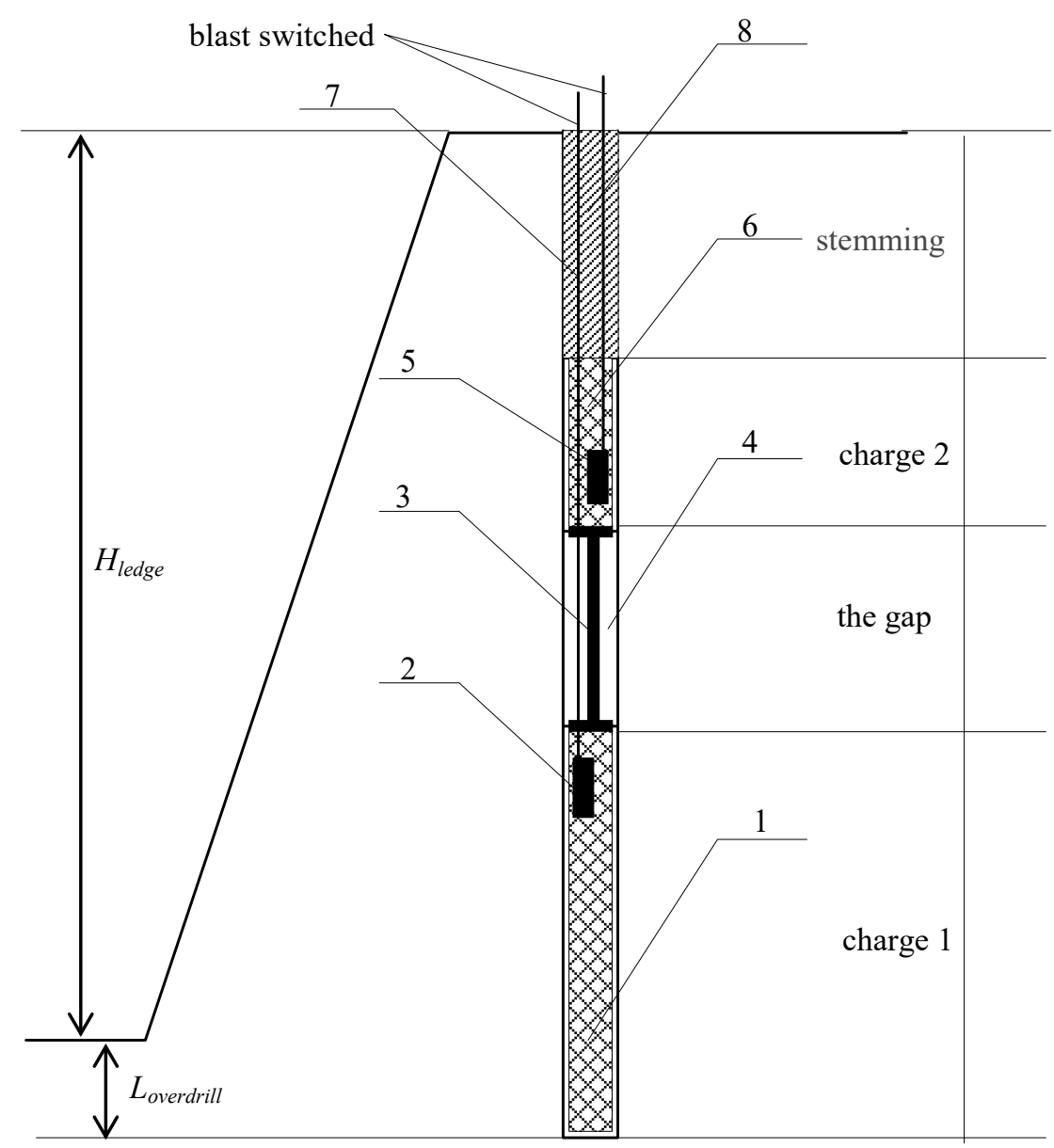

Fig. 4. Design of a borehole charge with an air gap. Designations: 1 - lower explosive charge; 2 - intermediate detonator; 3 - gap device; 4 - air gap; 5 - intermediate detonator; 6 - top explosive charge; 7 - thread detonation cord or non-electric initiation systems; 8 - stemming; $H_{\text {ledge }}$ - ledge height, $L_{\text {overdrill }}$ - overdrill.

\section{Conclusions}

In addition, as a result of the concentration of the explosion energy in the lower part of the ledge with continuous charges, an intense emission of detonation products is observed along the entire front of the ledge and an increased seismic effect on nearby buildings.

Experimental explosions of charges dispersed by air gaps showed that in the presence of air gaps, the energy of the explosion is transmitted to the rock mass with a certain delay, and the stresses in the array are distributed more evenly, and the interference of the blast waves occurs in several planes in a large volume of rock.

The only difference in the pilot test was to reduce the number of explosives in the well from 15 to $25 \%$. The results of the pilot test turned out to be positive: the crushing of the rock occurs more evenly than with continuous core charges.

At wells with air gaps, pins and camber widths decreased, but in general, the explosive energy use factor increased.

Thus, the dispersal of charges by air gaps increases the degree of useful use of explosive 
energy, as evidenced by the improvement of crushing while reducing the consumption of explosives.

The use of charges dispersed by air gaps is a kind of "mechanization" of blasting, represents a significant reserve for further improving the quality of blasting and helps to reduce the cost of production.

In all the above quarries, the results of the explosion showed the advantages of the new method and made it possible to switch to exploding dispersed charges with air gaps.

Based on the foregoing, it can be argued that the use of charges with air gaps is a means of controlling the energy of the explosion, allowing to achieve a more uniform crushing of rocks with a corresponding decrease in the specific consumption of explosives.

\section{References}

1. Varnakov, Yu.V. (2012). Analysis of existing emulsion explosives of class 2, designed for blasting with small diameter boreholes. Bulletin of the Scientific Center for the Safety of Work in the Coal Industry, (1), 22-24

2. Tambiev, P.G. (2013). The concept of creating emulsion explosives in SPE "Interrin" LLP Bulletin of the Scientific Center for the Safety of Work in the Coal Industry, (3), 1417

3. Tambiev, P.G. (2013). Granular explosives of the Igdarin brand for underground mining. Bulletin of the Scientific Center for the Safety of Work in the Coal Industry, (5), 18-23

4. Internet recourse: www.vibromaster.ru

5. Dobrynin, I.A. (2017). New Porous Saltpeter of Eurochem Company. Mining Information and Analytical Bulletin, (9), 15-19

6. Saprykin, I.Ye., Fedotenko, S.M., Grishin, S.V. (2007). Optimization of blasting operations at open pits of the coal companies "Kuzbassrazrezugol". Gornyi Zhurnal, (6), 14-18

7. Fedorov, S.A. (1964). Air gaps as a way to control the action of an explosion. Collection. "Vzryvnoe delo", 54(11), 220-221

8. Lavrov, G.M., Grigoryev, A.V. (1986.). On one of the methods of fixing charges in the well. Collection. "Vzryvnoe delo", 89(46), 123-124

9. Kantor, V.Kh. (1964). Development of new designs of borehole explosive charges and methods for their formation. Collection. "Vzryvnoe delo", 97(54), 220-222 